
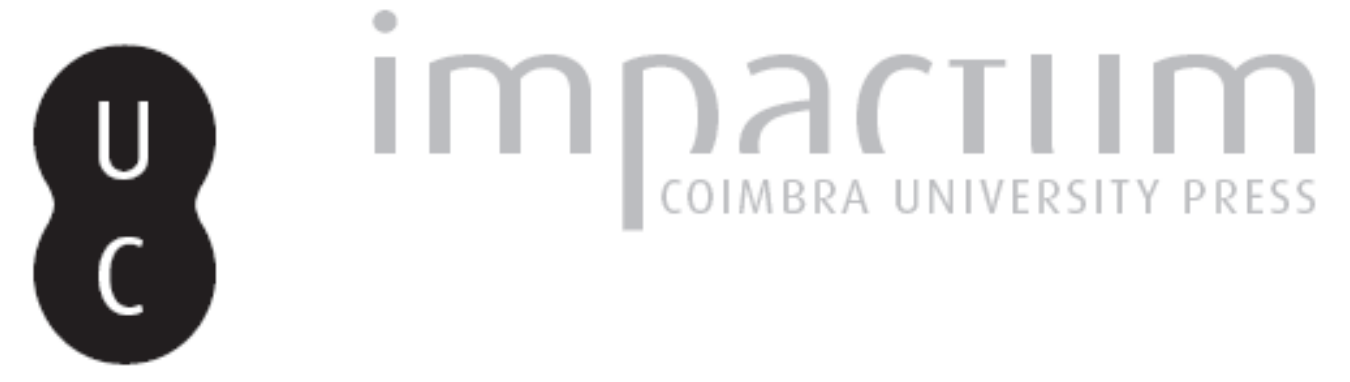

\title{
Características del ethos ibérico en Plutarco
}

Autor(es): $\quad$ Muñoz Gallarte, Israel

Publicado por: International Plutarch Society

URL persistente:

URI:http://hdl.handle.net/10316.2/37639

DOI:

DOI:http://dx.doi.org/10.14195/0258-655X_5_4

Accessed : $\quad$ 26-Apr-2023 09:34:49

A navegação consulta e descarregamento dos títulos inseridos nas Bibliotecas Digitais UC Digitalis, UC Pombalina e UC Impactum, pressupõem a aceitação plena e sem reservas dos Termos e Condições de Uso destas Bibliotecas Digitais, disponíveis em https://digitalis.uc.pt/pt-pt/termos.

Conforme exposto nos referidos Termos e Condições de Uso, o descarregamento de títulos de acesso restrito requer uma licença válida de autorização devendo o utilizador aceder ao(s) documento(s) a partir de um endereço de IP da instituição detentora da supramencionada licença.

Ao utilizador é apenas permitido o descarregamento para uso pessoal, pelo que o emprego do(s) título(s) descarregado(s) para outro fim, designadamente comercial, carece de autorização do respetivo autor ou editor da obra.

Na medida em que todas as obras da UC Digitalis se encontram protegidas pelo Código do Direito de Autor e Direitos Conexos e demais legislação aplicável, toda a cópia, parcial ou total, deste documento, nos casos em que é legalmente admitida, deverá conter ou fazer-se acompanhar por este aviso.

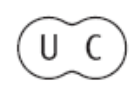




\title{
Características del ethos ibérico en Plutarco
}

\author{
por \\ Israel Muñoz Gallarte \\ Universidad de Córdoba \\ sulpice52@hotmail.com
}

\begin{abstract}
The aim of this paper is to research the concept of Iberian ethos in Plutarch's opera: what is what he has known about Hispania and what is the vision we have received from him?, what is the value of Plutarch's works as historical source? This investigation could be useful in several respects: 1) in offering all Plutarch's texts concerning Iberia, 2) in analysing these resources and 3 ) in revealing his knowledge and opinion about this Roman province.
\end{abstract}

Key-Words: Plutarch, Roman Lives, Iberian Ethos, Iberian Religion, Iberian Culture, Iberian Education, Roman Politics, Ancient Historiography, Iberian Anthropology.

fuentes más importantes para su historia.

Pocas regiones son consideradas por Plutarco con características tan contrapuestas como las referidas a Iberia, lugar elegido para exilio de ciudadanos romanos, pero también provincia ávida de revueltas que conducidas para sus propios fines por un general hábil, podían poner en dificultad al Imperio. En las siguientes páginas se abordará el estudio sistemático de la sociedad ibérica a partir de los textos de Plutarco, considerados como una de las
Una estimación rápida acerca de estas alusiones demuestra que Plutarco no tuvo interés especial por el pueblo íbero, si se tienen en cuenta, por un lado, las escasas descripciones que de él inserta el de Queronea y, por otro, los extensos trabajos que dedicaron a su historia autores como Tito Livio, Veleyo Patérculo, Valerio Máximo, Frontino, Floro, Apiano, Eutropio, Orosio, Diodoro, Estrabón o Salustio ${ }^{1}$. Además, los abundantes restos

Entre las fuentes no conservadas, de las que posiblemente hubieran bebido estos autores, se cuentan: Memorias de Sila, donde se relatarían los primeros años de las guerras sertorianas hasta el 78 a.C., momento de la muerte del autor, cf. D. GILlis, "Quintus Sertorius", RIL, 103 (1969), p. 712; L. Comelio Sisena, que trató en su obra, compuesta por doce libros, la Guerra Social y la que enfrentó a Mario y a Sila, donde debería aparecer la figura de Sertorio y, por tanto, el pueblo íbero, cf. A. Schulten, Sertorio, Barcelona, 1949, p. 29 y W. BENNET, "The death of Sertorius and the coin", Historia, 10 (1961), p. 467; M. Terencio Varrón, que participó en las Guerras sertorianas en el bando pompeyano, cuyo relato de las acciones bélicas, de primera mano, hubo de influir en los autores posteriores; Galba, citado por Orosio \{Hist. 5.23,9), quien relató la llegada de 
arqueológicos íberos del patrimonio hispano-portugués también muestran una avanzada sociedad inmersa en un rápido proceso de romanización, que Plutarco sólo esboza con rápidos trazos.

Los pasajes referentes a la sociedad íbera se encuentran principalmente en Vidas, mientras que en Moralia no aparecen más que unas pocas y breves alusiones. Dentro del grupo de Vidas, es en aquellos personajes que tuvieron un estrecho contacto con esta región, militar principalmente, en los que el autor de Queronea inserta las más extensas noticias. Así, en las páginas que siguen se analizarán los textos, tras clasificarlos en los siguientes apartados bajo los que Plutarco, no de manera sistemática, describe esta sociedad: religión, educación, política y trabajo.

\section{RELIGIÓN}

Apenas aparecen alusiones a la religión y costumbres de los íberos ${ }^{2}$; únicamente se pueden contar cuatro en la obra plutarquea y una más en el De Fluviis pseudoplutarqueo. Dichas menciones, además, aunque recogen ciertas características importantes para el conocimiento de la religión indígena, describen, más bien, un pueblo en un proceso de romanización ya avanzado, datable entre los ss. I a.C. y III-IV d.C., es decir, cuando la religión indígena ha experimentado las influencias de pueblos colonizadores, ya sea el griego, ya sea el cartaginés o el romano ${ }^{3}$.

El testimonio históricamente más antiguo es el de Moralia, Regum et imperatorum apophthegmata 4 , donde el de Queronea hace referencia, en tiempos de Escipión el Africano mayor (210 a.C.), a

Pompeyo a la Península y, además, abuelo del emperador Galba, cf. D. GiLlis, 1969, p. 713; Teófanes de Mitilene, mencionado por Plutarco \{Pomp. 37) y Cicerón (Arch. 24), que habría compuesto una biografía de Pompeyo. También hay que tener en cuenta numerosos testigos oculares del bando pompeyano o sertoriano que, posteriormente, sirvieron de fuente a autores grecolatinos como Salustio, cf. A. SCHULten, 1949, p. 26. Acerca de las fuentes relativas a la vida de Sertorio, cf. M. L. NeIRA JIMÉNEZ, "Aportaciones al estudio de las fuentes literarias antiguas de Sertorio", Gerión, 4 (1986) 189211; L. PÉrez Vilatela, "Fuentes, geografía y paisajes del Sertorio", en J. García LÓPEZ-E. CALDERÓN DORDA (eds.), Estudios sobre Plutarco: paisaje y naturaleza. Actas del II Simposio Español sobre Plutarco, Murcia, 1990. Madrid, 1991, pp. 319-326.

Puede consultarse una bibliografía actualizada sobre la religión indígena de Hispania en J. Ma , BLÁZQUEZ, Religiones primitivas ibéricas tomo II. Religiones prerromanas, Madrid, 1983; también cf. M. SALINAS DE FRÍAS, "La religión indígena de la Hispania central y la conquista romana", Hispania Antiqua, 11-12 (1981-1985), p. 307, ๆ. 1.

Testimonio de este influjo son los objetos de culto orientalizantes, amuletos, representaciones semíticas o egipcias halladas en la Meseta, llegadas por el comercio púnico; cf. J. PADRO, "Amuletos y divinidades egipcias en la Hispania prerromana" en J. Ma. BLÁZQUEZ (ed.), 1983, p. 465. 
un templo en honor de Afrodita $^{5}$ en la ciudad de Baria ${ }^{6}$, como lugar en el que se va a celebrar un juicio entre dos litigantes ${ }^{7}$. En este ejemplo se observa la existencia de un edificio ya romano, cuyas funciones son las típicamente romanas $^{8}$, fruto de la asimilación de creencias foráneas e indígenas, favorecida por el sincretismo propio de la religión y cultura del Alto Imperio9.

En el resto de las citas se describen prácticas propias de un pueblo tribal y bárbaro. En primer lugar, se refiere a la costumbre de los sacrificios humanos $\mathrm{y}$, en segundo, a la superstitio, como arma utilizada por los romanos para manipularlos ${ }^{10}$.

En cuanto a los sacrificios humanos, se hace una mención en Moralia, sin explicar las causas de este acto ${ }^{11}$ :

¿Por qué cuando supieron (scil. los romanos) que los llamados bletonesios ${ }^{12}$, un pueblo bár-

Posiblemente en honor de Venus marina; cf. A. SCHUlten, Fontes Hispaniae Antiquae III, Barcelona, 1935, pp. 118-119. Éste no es el único testimonio que hace referencia al culto dedicado a Afrodita/ Venus, sino que se cuenta con otras noticias como la de App., Hisp. 64, en la que se relata cómo Viriato acampó en un monte de olivos dedicado a esta divinidad, situado en la Carpetania, posiblemente en la Sierra de san Vicente, 146 a.C.; cf. M. SALINAS DE FRÍAS, 1981-1985, p. 308.

6 En el texto aparece $\pi$ ó $\imath v$ BaOciav, posiblemente Baria, identificada con Villaricos o Vera. Ambos lugares pertenecen a la costa de Almería, al sudoeste de Cartago Nova, donde Escipión desarrolló su campaña del 209 a.C. El acontecimiento tendría lugar el 208 a.C. La anécdota también aparece en Val. Max., III 7.1 y Gell., VI 1; cf. R. Ma. Aguilar, "Política romana en Hispania", en I. Gallo-B. SCARdigli (ed.), Teoría eprassi politica nelle opere di Plutarco. Atti del $V$ Convegno plutarcheo, Certosa di Pontignano, 7-9 giugno 1993, Nápoles, 1993, p. 16, n. 1.

7 Un buen ejemplo del proceso de romanización en la Península ibérica y de la consecuente adaptación o sincretismo de divinidades indígenas y foráneas lo constituye la ciudad romana de Valeria; cf. M. DURAN MAÑAS-I. MuÑOZ Gallarte, "La Valeria romana”, Revista de Arqueología del s. XXI, 290 (2005) 40-49.

8 Plutarco nunca considera a los romanos bárbaros, sino que los asimila en cultura y civilización a los griegos; cf. C. J. D. AALDERS, Plutarch s Political Thought, Amsterdam, 1983 , pp. 13 y 20.

Cf. M. SALINAS DE FRÍAS, 1981-1985, pp. 310 y 317. Antes de la romanización se desconoce la existencia de templos construidos dentro de ciudades o poblados indígenas, dedicando al culto otros recintos naturales friera de las poblaciones, como bosques o montes; cf. J. Ma. BLÁzQUEZ, "La religiosidad de los pueblos hispanos vista por los autores griegos y latinos", Emerita 26 (1958), p. 79-81.

10 Plutarco acepta que la superstitio bárbara sea utilizada por los romanos; cf. C. J. D. AALDERS, 1983, p. 53.

11 Cf. Plu., Mor. 83.283.

12

Probablemente oriundos de Ledesma (Salamanca).

PLOUTARCHOS, n.s5 (2007/2008) 43-64.

ISSN 0258-655X 
baro, mataban un hombre en honor a sus dioses, mandaron venir a sus jefes a castigarlos, pero como lo hacían, al parecer, conforme a una costumbre los dejaron en libertad y solamente lo prohibieron en el futuro? ${ }^{13}$.

Esta medida coercitiva propuesta por P. Craso, cónsul de la Ulterior del 95-94 a.C., es la única mención que Plutarco hace de los dioses íberos, sin extenderse en su naturaleza, ni tampoco en las razones que les llevan a esta práctica ${ }^{14}$.

Sobre los sacrificios humanos aparece otra mención en la Vida Sertorio 14, 5:

Es costumbre de los íberos que, quienes forman la guardia del jefe, mueran con él cuando éste cae y los bárbaros de allí lo llaman sacrificio.
Ambos ritos requieren la muerte de personas, pero se diferencian en que mientras el primero va dirigido simplemente a "sus dioses", haciendo Plutarco uso de un término muy usual en la lengua griega, $\tau^{\wedge} \theta v \kappa \varepsilon ́ v \alpha l$ ("hacer una ofrenda" cruenta o no a los dioses); el segundo, aunque se designa con un término poco

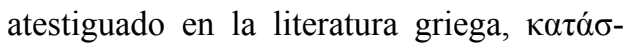
$\tau \tau^{\prime} \operatorname{E}^{\circ} \sigma 1 \zeta^{15}$, es una práctica bien conocida, la devotio ibérica. Se trata de un rito de origen celta ${ }^{16}$, según el cual se creaba un vínculo entre general y soldado, parecido al de la clientela romana, pero en el que además de la fidelidad hacia el patrón, en este caso, relacionada con las armas, se exigía acompañarlo en la muerte ${ }^{17}$. En todo caso, el uso de términos distintos implica que ambos ritos eran diferentes para Plutarco. Acerca del primero apenas ofrece información, quizá por desconocimiento, pero el segundo implica un esfuerzo de análisis de las fuentes de que disponía .

Las traducciones de los textos plutarqueos han sido tomadas de R. Ma. Aguilar, Fontes Historiae Antiquae IV (en prensa).

Este sacrificio podría estar dirigido a la divinidad indígena relacionada con la guerra, Cosus o Coro, asimilada, posteriormente, a Ares o Marte; cf. M. SALINAS DE FRÍAS, 1981-1985, p. 321.

15 Plutarco utiliza este término en cinco ocasiones, pero las cuatro restantes hacen referencia a otro rito, la libación; cf. Plu., Alex. 69.6; Mor 435B.9, 437B.6 y 438A.9.

16 Cf. H. G. LIDDELL-R. SCOTT, Greek-English Lexicón, Oxford, 1996, s.v.

17 "La devotio en Hispania la compartían íberos y celtas, pero desde luego existía en la Europa occidental indoeuropea por influencia céltica"; cf. R. Ma. AGUILAR-L. PÉREZ Vilatela, Plutarco, Vidas de Sertorio y Pompeyo, Madrid, 2004, p. 77 n. 106. Front., Strat. 3.2,4, ofrece otro testimonio de sacrificios colectivos cuando Viriato cayó sobre Segóbriga (Cuenca).

Como algunos estudiosos han demostrado, las acusaciones de sacrificios humanos a pueblos bárbaros son, en ocasiones, incluso un simple topos literario. En el contexto de la literatura cristiana primitiva, cf. L. ROIG LANZILLOTTA, "The Early Christians and Human Sacrifice” (en prensa). 
Aunque no se conocen las causas específicas de estos sacrificios humanos, se ha propuesto que, por analogía con los pueblos celtas de la Galia, estos rituales tendrían dos finalidades: vaticinar o purificar una impureza anterior ${ }^{19}$.

Las otras referencias a la religión íbera, en realidad, una acusación de superstitio, aparecen en el relato de la cierva blanca de Sertorio $^{20}$, datado tras la batalla de Suero en la Albufera de Valencia, el año 75 a.C. Desde el principio de la historia, Plutarco explica que todo fiie una estratagema de Sertorio para manipular a los primitivos y crédu-

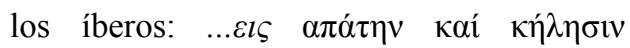
$\varepsilon \dot{\varepsilon} \mu \eta \alpha$ $\alpha \alpha ́ \tau o$, “...para manejarlos mediante el engaño y el encantamiento”.

Según el relato, un cazador encuentra y captura una cierva de color blanco que regala como presente al general romano, quien, tras domesticarla y descubrir en ella algo divino, la utiliza adjudicándole poderes adivinatorios, inspirados por la diosa Ártemis ${ }^{21}$. Siendo Sertorio consciente de que "la índole de los bárbaros es asequible por naturaleza a la supersti-

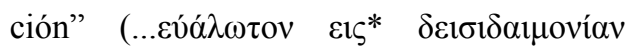

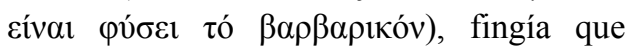
le hablaba en sueños y le ordenaba que tuviera dispuestas las tropas o, si tenía conocimiento de una buena noticia por un mensajero, la hacía avanzar coronada, antes de dar a conocer lo ocurrido. Que esta cierva acompañara a Sertorio hacía

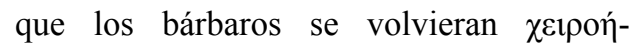
$\theta \varepsilon 1 \varsigma, \quad$ "manejables", y $\mu \varepsilon \tau \rho ı \tau \varepsilon \rho \rho \varsigma^{*}$, "más moderados", pues pensaban que servían a un dios y no a un hombre.

Un poco después, en el mismo relato de la Vida de Sertorio, tras la noticia de la muerte de su madre, el protagonista, según Plutarco, “estaba terriblemente

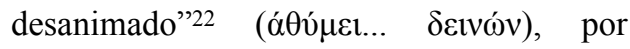
la desaparición de la cierva, al igual que su ejército, que pierde su confianza en el general romano. Pero todo se resolverá al encontrarla y poder, de nuevo, utilizarla para el mismo fin. Así, Sertorio espera unos días con la cierva escondida, hasta que se presenta en la tribuna anunciando un sueño favorable a los jefes bárbaros, momento en el que deja suelto al animal, que se acerca a su amo dejándose acariciar. De este modo, Sertorio recobra el crédito perdido e incluso su "apariencia divina".

Estas características y las prácticas que Sertorio llevaba a cabo, según el relato de Plutarco, parecen calificarlo no sólo como

20 Cf. Plu., Sert. 11.6-8; 20.1-2. También se relata esta misma historia en Valerio Máximo I, 2,4; Plin., HN 8.117; Front., Strat. 1.11,13; App., BC. 1.110; Gell., XV 22.

21 Ciertas similitudes con esta actuación aparecen en Escipión (cf. Plb., X 2.5; 9.2; 11.7 ; Liu., XXIV 19.7) y Cayo Mario (cf. Plu., Mar 17). 
general de los íberos, sino también como su sacerdote o profeta, vinculado estrecha-

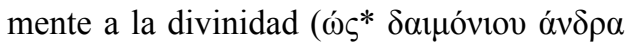
$\kappa \alpha 1$ Ocols* $\left.\varphi i^{\prime} \lambda \mathrm{v}^{23}\right)$. Incluso se pueden establecer ciertas semejanzas comunes a Sertorio y a otro conocido general celtíbero, Olíndico, según el relato de Floro ${ }^{24}$.

La anécdota sirve a Plutarco para defender una idea concreta: frente a la superior cultura grecolatina, la religión de los íberos se basa en la credulidad ciega y la deisidaimonía ${ }^{25}$. Aunque es conocido que Artemis recibía importantes honores en la Hispania romana, quizá por su carácter agreste, parece que esta estratagema no sólo se dirigía a los soldados íberos, sino también a los romanos. De hecho, Diana fue la primera deidad extranjera en entrar oficialmente en el panteón romano ${ }^{27} \mathrm{y}$, como Plutarco refiere, en los templos de esta diosa en Italia se mostraban cornamentas suspendidas de ciervos . Además, se sabe que Diana era una divinidad destacada en territorio sabino, lugar de nacimiento de Sertorio ${ }^{29}$. Así, puesto que este tipo de culto a Diana se encuentra igualmente extendido tanto en Iberia como en Roma y Grecia ${ }^{30}$, Sertorio sólo tuvo que anudar los cabos necesarios. No obstante, parece que en Hispania esta
23

24

25

26 
divinidad adquirió características propias, como la adivinación, pues no tenemos noticia de oráculos dispensados por Ártemis/Diana en la Antigüedad.

Más esclarecedor acerca de la religión íbera ante los ojos de un romano resulta el siguiente texto, en el que, en primer lugar, Plutarco dice que Sertorio estaba "terriblemente desanimado" $\delta$ ió

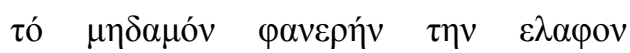

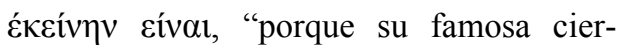
va no aparecía por parte alguna", con lo que parece que el general tenía un vínculo especial con esa cierva y, quizá, no fuera tan insensible a las facultades prodigiosas de las que había hecho alarde ante los íberos. Además, a continuación, el autor comenta cómo Sertorio deja suelta a la cierva en la tribuna pretorial y militar, la cual no debería de estar compuesta únicamente por los jefes de pueblos hispanos, como Plutarco destaca, quienes podían haber accedido a este puesto como socii por gracia de Sertorio, sino también por romanos .

Así, apenas aparecen noticias de la religión íbera en Plutarco, que se muestra más interesado por el ritual íbero y, especialmente, por aquellos actos 'exóticos' o 'curiosos', que se alejan del crisol religioso grecorromano . Acerca de las divinidades a las que se rendía culto en la Península únicamente se ofrece testimonio de las romanas asimiladas, Afrodita y Artemis, como se ha observado.

Un fragmento de la obra pseudo-plutarquea De fluviis es la única noticia referente a una divinidad indígena rastreable en la epigrafía ibérica, Lug. El texto afirma lo siguiente ${ }^{33}$ :

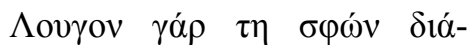

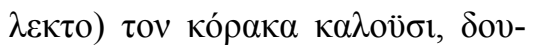

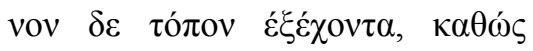

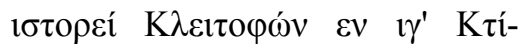
$\sigma \varepsilon \omega v$.

Pues llaman Lug, en su idioma, al cuervo, añadiendo "dunum" por lugar (scil. Lug-dunum), según recoge Clitofonte en el capítulo 13 de las Fundaciones.

Aunque el texto hace referencia a una divinidad de las islas británicas, su aparición en la epigrafía española ${ }^{34}$ y en topó-

Seguimos, por tanto, la interpretación de R. Ma. AgUilar-L. PÉrEZ Vilatela, 2004, p. 87, ns. 122-123.

32 Un destacado motivo que une ambas culturas es el "paso del río Leteo"; cf. Plu., Mor. 34.273D: “¿Era éste (se. D. Bruto) el que invadió Lusitania y el primero en atravesar con su ejército, aún más allá, el río Leteo?”. El breve fragmento es adscrito por la crítica como un ejemplo más de la superstición íbera, cf. J. Ma. BLÁZQUEZ, 1958, p. 103.

34 Cf. A. TOVAR, "El dios céltico Lugu en España", La religión romana en Hispania, Symposio organizado por el Instituto de Arqueología "Rodrigo Caro" del C.S.I.C., del 17 al 19 de diciembre de 1979, Madrid, 1981. Aquí se recoge todo el material epigráfico, que alude a Lug/Lugu, del que destacamos la inscripción de Peñalba de Villastar 
nimos, como el hispano Lucus ${ }^{35}$, demuestra la generalización uniforme de su culto en todo el territorio celta, insular y continental. El texto pseudo-plutarqueo establece una relación de la figura mítica Lug con el cuervo ${ }^{36}$, lo que ha llevado a pensar, por un lado, que pudiera establecerse una conexión con el dios grecorromano Apolo y, por otro, sobre la base de una identificación realizada por Julio César ${ }^{37}$, con Mercurio. No obstante se advierte que esta figura religiosa es sumamente compleja, pudiendo también ser clasificado como "un dios mago, sacerdotal"38.

\section{EDUCACIÓN.}

Es muy escasa la información que ofrece Plutarco sobre la educación, recogiendo sólo la historia de la llamada "escuela de Osea", inserta en el relato de la Vida de Sertorio, 77-76 a.C. ${ }^{39} \mathrm{Al}$ autor parece sorprenderle la noticia de que Sertorio se preocupara por la educación de los hijos de íberos nobles y la refiere del siguiente modo ${ }^{40}$ :

Pero lo que más les subyugó fue el trato que daba a sus hijos. En efecto, congregó en Osea, una ciudad grande, a los más notables entre los pueblos y les puso maestros de enseñanzas griegas $y$ romanas; en realidad los retenía como rehenes, pero de palabra los educaba para hacerles participar en el gobierno y el poder cuando se hicieran hombres. Sus padres estaban llenos de gozo al ver a sus hijos con togas praetextas frecuentando la escuela con gran decoro y al ver que Sertorio pagaba sueldos por ellos; muchas veces recibía sus demostraciones de conocimientos, repartía premios a los más aprovechados y les regalaba esos collares de oro que los romanos llaman bulas ${ }^{41}$.

(Teruel), el ara de UxamaMs dos aras procedentes de Agreda y Pozoblanco, las tres dedicatorias en la provincia de Lugo y una más de Santander.

35 En el continente europeo existen otros topónimos creados a partir de la raíz Lug, como Laon, Liegnitz o Leiden; cf. M. SALINAS DE FRÍAS, 1981-1985, p. 312.

36 El citado epígrafe de Peñalba de Villastar (Teruel), bajo cuya inscripción aparece la figura de un ave que pudiera tratarse de un cuervo, apoyaría la relación establecida por el texto pseudo-plutarqueo Lug-cuervo.

Caes., Ciu. 6.17.

38 Cf. M. SALINAS DE FríAS, 1981-1985, p. 313.

39 Cf. Plu., Sert. 14.3-4; 25.6. Acerca del momento fundacional y la naturaleza de esta "escuela", cf. R. Ma. AGUILAR, 1993, p. 21, n. 15.

40 Plu., Sert. 14.3-4.

41 La toga praetexta y la bulla eran los rasgos distintivos de la vestimenta infantil en los niños romanos. El uso de la praetexta, túnica blanca con una franja roja en los bordes, se prolongaba hasta la edad comprendida entre los quince y dieciocho años, momento en el que se cambiaba por la virilis, en una fiesta de importante significado religioso, cele- 
Según se lee en el texto griego, Sertorio congregó en Osea a los hijos menores de siete años $(\pi \alpha 1 \delta \omega ́ v)$ de los notables íberos $\left(\beta \hat{\gamma} \gamma \beta v^{\wedge} \sigma \tau \alpha \dot{\tau} \tau o v \varsigma^{*}\right)$, a los que ofreció una educación a través de maestros de las lenguas griega y latina, constituyendo lo que ha venido a llamarse la "primera Universidad en Hispania". Si se tiene en cuenta que, según los documentos conservados, ya hay noticias del trabajo de profesores de lenguas clásicas en Iberia -como es el caso de la estancia de Asclepíades de Mirlea, profesor de gramática griega, en la Bética a principios del s. I a.C. ${ }^{42}$, -en este momento, entre el 78 y 72 a.C.43, ya debía existir en esta región una primigenia red educa- tiva, compuesta por pedagogos, gramáti$\cos \mathrm{y}$ retóricos latinos y griegos. Éstos, atraídos por las amonedaciones de la Hispania Citerior, irían de ciudad en ciudad, al modo de los sofistas, siendo contratados por la elite íbero-romana con el propósito de formar a futuros políticos $\mathrm{y}$ representantes del Imperio Romano.

Así, un proceso de romanización en avance se vio dinamizado gracias a la actividad de Sertorio, quien, al interesarse por la educación de estos niños, conseguía estrechar lazos con los indígenas notables y asegurarse generaciones de jóvenes, educados según las costumbres romanas, que apoyarían su proyecto político. Estas intenciones explicarían por qué

brado en el mes de marzo; cf. RE VI A, 2 cois. 1651-1660, s.v. toga. En cuanto a la bulla, se trata de una prenda tomada de los etruscos, adomo colgado del cuello en forma de media luna, confeccionado en metal y cuero, que podían portar los niños romanos libres cuando ya eran capaces de pronunciar un discurso. Su carácter era básicamente apotropaico y su uso se mantuvo durante época cristiana, aunque modificando su forma por emblemas cristianos; cf. $R E$ III 1, cois. 1048-1051 s.v. bulla; Val. Max., V 6.8 y Schol. Iuv. V 164.

42

43

44

Diferimos, por tanto, de la hipótesis propuesta por F. García Morá en ciertos puntos: en primer lugar, la creación de una "escuela" en Osea supone una innovación, sin poder asemejarse a los casos de Escipión y T. Sempronio Graco, puesto que en estos ejemplos no aparece la educación de los rehenes; en segundo lugar, si creemos las palabras de Plutarco, difícilmente se pueden explicar los esfuerzos de Sertorio, si de rehenes únicamente se tratara. Como a continuación se explica, suponemos que el trágico final de la escuela de Osea influyó en que Plutarco afirme que la única intención de Sertorio íue la de controlar unos rehenes. Acerca de las causas del fin de la "escuela" de Osea, se ha de tener en cuenta la situación de Sertorio poco antes de su disolución, cuando Pompeyo, ya llegado a Hispania, comienza a ejercer su poder atrayéndose a las tribus hispanas. Así, parece que la respuesta de Sertorio fue la represalia, para acabar con las defecciones producidas o en proceso. No obstante, aceptamos que, desde un principio, Sertorio también pretendía ejercer un control político-militar sobre la elite indígena. Acerca de la escuela de Osea, cf. F. GARcíAMORÁ, 1991, pp. 173-175; D. PLÁCIDO, "Sertorio", Studia Histórica, Historia Antigua VII (1989), p. 98. 
Sertorio permitió que algunos indígenas de gran peso político fueran accediendo a estamentos gubernativos, como la tribuna citada en el relato de la cierva blanca.

Pero, en opinión del autor, la finalidad del esfuerzo educativo llevado a cabo por Sertorio es una estratagema para mantener controlados a los íberos notables. Quizá Plutarco haya extraído esta idea del trágico final de la "Universidad de Osca", a la cual se refiere más adelante en la Vida de Sertorio, de la siguiente manera:

...de tal modo que Sertorio, cambiando su primitiva moderación $\mathrm{y}$ bondad, cometió un terrible crimen con los hijos de los íberos que se educaban en Osca: a unos los mató, a otros los vendió como esclavos ${ }^{45}$.

Esta actuación estuvo motivada, según Plutarco, por el momento crítico que vivió Sertorio, al observar que partidarios suyos se pasaban al bando pompeyano, desde finales del 75 a.C $46, y$ cómo su férrea dirección de los pueblos indígenas iba mermando por la corrup- ción de aliados romanos suyos como Perpena ${ }^{47}$. Estas traiciones alejaban al general de su sueño de regresar a Roma, descrito por el de Queronea en los siguientes términos: "Pues era también un patriota y sentía un gran deseo de regresar"48. Otra posible causa de esta represalia contra los niños de Osea sería la depresión en la que Sertorio se sume tras conocer la noticia de la defunción de su madre.

\section{POLÍTICA.}

Los textos de Plutarco permiten reconstruir el lugar que ocupaba Hispania dentro del crisol social que componía el Imperio Romano. Para este autor, la Península era, principalmente, un lugar de destierro para aquellos romanos que no habían encontrado su lugar en el gobierno o comenzaban su cursus honorum, pues los bárbaros ofrecían numerosas oportunidades para, haciendo méritos, ascender más rápidamente. Los casos que recoge Plutarco de estos exilios son numerosos; así, en la Vida de Sertorio afirma claramente ${ }^{49}$.

Cf. Plu., Sert. 25.6.

Cf. F. GARCÍA MORA, 1991, p. 270.

Cf. Plu., Sert. 25-26.

La exaltación plutarquea de Sertorio como prototipo de patriotismo tendría su origen en otras fuentes de época imperial como Salustio. Estos ideales estarían basados en la tradición cínico-estoica reflejada en la obra de Posidonio, muy utilizada por el propio Salustio; cf. R. Ma. AGUILAR, 1993, p. 26, n. 28; L. A. GARCíA MORENO, "Paradoxography and Political Ideals in Plutarch's Life of Sertory", en PH. A. STADTER (ed.), Plutarch and the Historical Tradition, Londres y Nueva York, 1992, pp. 147-148.

Cf. Plu., Sert. 6.4-5. 
Desesperado (scii. Sertorio) totalmente de la ciudad partió a Iberia, para ser aquí un refugio de sus compañeros en desgracia, si se adelantaba a hacerse con el poder.

Del mismo modo, en la Vida de Galba, refiriéndose a Otón, gobernador de la Lusitania ${ }^{50}$, se comenta:

No se mostró desagradable ni torpe con los súbditos, sabiendo que este gobierno le había sido confiado como paliativo y pretexto de su exilio.

La situación de Iberia a la llegada de Sertorio, en calidad de propretor el 83 a.C., se ajusta a la descripción de lugar de exilio que realiza Plutarco, según la cual Hispania estaba compuesta por numerosos pueblos bárbaros de características tribales $^{51}$. Entre ellos destaca el autor el ejemplo de los caracitanos, quienes "no vivían en ciudades o aldeas, sino en una colina de gran tamaño y elevada que contiene cavernas y concavidades en las rocas", dedicándose al bandidaje y escondiéndose por miedo a la guerra en las inexpugnables grutas, hasta la llegada del ejército de Sertorio ${ }^{52}$.

Las ciudades indígenas son apenas descritas por el de Queronea, que, más interesado por los enfrentamientos bélicos, tan sólo ofrece un detalle de una de ellas: la falta de previsión hidráulica de la capital de los lacóbrigues, por lo que resultaba fácil de tomar en un asedio ${ }^{53}$. Muy distinto es el ambiente en las ciudades ya romanizadas, como Corduba, de la que se describe un festejo de victoria en favor de Metelo en los siguientes términos ${ }^{54}$ :

50 Cf. Plu., Galb. 20.1-4. Plutarco aclara la concepción que había de Hispania en la capital del Imperio en Luc. 34.4: "Lucharon (scil. los soldados pompeyanos) contra desterrados en Iberia y contra esclavos en Italia". Según Suet., Otho 7,2, el cargo del futuro emperador fue el de legatus Augusti pro praetore.

51 Cf. R. Ma . Aguilar, 1993, pp. 20-21.

${ }^{52}$ Cf. Plu., Sert. 17.1-3.

53 El término griego $\pi$ ó $\lambda \iota \varsigma$, en Estrabón, Diodoro y el mismo Plutarco recoge los conceptos de vicus, oppidum y castellum, poblaciones en lento proceso romanizador en tomo a las cuales se estructuraban las gentilitates. Existe cierta unanimidad en situar a los caracitanos en Tarcacena, a unos cuatro kilómetros al nordeste de la actual Guadalajara. Acerca del debate suscitado por las palabras de Plutarco, cf. F. GARCÍA MORA, 1991, pp. $152-155$.

54 Cf. Plu., Sert. 22.2-4. Bien distinta era la forma de celebrar las victorias de Sertorio, quien demuestra una gran austeridad, cf. Plu., Sert. 26.7-9: "Las comidas de Sertorio se celebraban siempre con gran respeto y decoro, porque no soportaba ver ni oír ninguna indecencia, y acostumbraba a tratar a sus compañeros de mesa con bromas discretas y sin excesos". Obsérvese la oposición entre las celebraciones típicamente romanas de una victoria y ésta hispano-romana. Quizá Plutarco, en este texto, además de mostrar clara- 
Se hizo proclamar imperator y las ciudades le recibían a su llegada con sacrificios y altares. Se dice que aceptaba ceñirse con coronas y banquetes de festines grandiosos, en los que bebía con vestiduras triunfales. Estatuas de Victorias, que se desplazaban mediante mecanismos de poleas, hacían descender a sus pies trofeos de oro y coronas, y coros de niños y mujeres le cantaban himnos de victoria.

Otro elemento característico de la Iberia prerromana es su enfrentamiento mutuo entre distintas tribus indígenas, como aparece en la Vida de César ${ }^{55}$, noticia situada cronológicamente durante su pretura, 61-62 a.C.: "Dispuso bien (scil. César) los asuntos de la guerra, pero no organizó peor los de la paz, restableciendo la concordia entre las ciudades...".

La única virtud de estos pueblos era que la joven región indómita ofrecía posibilidades para que un romano habilidoso se hiciera con mucho poder. Los culpables de esta situación no eran sólo los malos gobiernos bárbaros, sino también la corrupción y los excesos de los generales romanos, según la Vida de Sertorio ${ }^{56}$ :

Allí se asoció con pueblos numerosos y florecientes por sus jóvenes, pero mal dispuestos respecto a todo gobierno por los excesos y soberbia de los generales que habían llegado sucesivamente.

Esta corrupción también mancha a los soldados, quienes :

cometían excesos, por vivir en la abundancia y estaban borrachos las más de las veces; los bárbaros, despreciándolos, hicieron venir por la noche ayuda de sus vecinos de Isturgi $\mathrm{y}$, atacándolos en las casas, los mataban.

En este escenario, los levantamientos son la única vía a la que recurren los indígenas a lo largo de los años de dominio romano y de las vidas de los gobernadores que comenta Plutarco. Lucio Paulo Emilio se enfrentó a la revueltă $\mathrm{del}$ año 191 a.C., que, por los datos del contingente,

mente su simpatía por Sertorio, le aplique características más propias de los austeros íberos, como también ocurre con sus descripciones de la milicia sertoriana. En contraste, Metelo parece seguir costumbres típicamente orientalizantes, pero, aunque la clientela ibérica fue una institución de gran fuerza, no debe confundirse la fidelidad de los clientes con el culto al patrono; cf. F. RODRÍGUEZ ADRADOS, "La fides ibérica", Emérita, 14 (1946) 128-209. También se debe tener en cuenta que la "iniciativa y disposición de las ceremonias se debía a romanos y no a indígenas españoles”, cf. A. D’ORS PÉREZ PEIX, "Sobre los orígenes del culto al emperador en la España romana" Emerita 10 (1942) 197-227.

55 Cf. Plu., Cara. 12.

${ }^{56}$ Cf. Plu., Sert. 6.7-9.

${ }^{57}$ Cf. Plu., Sert.3.6-7.

58 Otra revuelta por parte de los cántabros es referida por Plutarco: cf. Plu., Mor. 9.322BC; cf. R. Ma. AgUILAR, 1993, pp. 16-17. 
debió ser muy importante, pues fue enviado Paulo Emilio "en calidad de general, no con seis fasces como tienen los pretores, sino con otras tantas además, de modo que la dignidad de su mando fue la de cónsul" 59 .

La entrada de la política romana $y$, por tanto la romanización de los indígenas, supone, para Plutarco, el único posible avance civilizador de Iberia. Los primeros intentos de los pretores y cónsules se basaban en la fuerza, en conseguir la paz mediante la represión de las revueltas y la compra de los notables íberos $^{60}$. En la Vida de Paulo Emilio es descrita su política conciliadora "en paz y fidelidad"61, por lo cual fue muy apreciado por los íberos:

Cuantos íberos, ligures y macedonios se encontraban casualmente en Roma, los más fuertes y jóvenes cargaron el lecho funerario y lo transportaron; los más viejos lo acompañaban, llamando a Emilio 'benefactor' y 'salvador de la patria' 62 .
En este texto, Plutarco parece referirse a íberos ya romanizados. La misma recopilación de esta noticia supone que pueblos hispanos habrían apreciado la paz conseguida, aún habiendo llegado a ella tras duras derrotas de compatriotas frente al ejército de Paulo Emilio ${ }^{63}$.

Un intento de realizar una política distinta está recogido en la Vida de Sertorio $^{64}$, quien supo conjugar las esperanzas de libertad del pueblo indígena, cuyas "armas, dinero y ciudades" 65 emplearía para sus fines. Al tiempo, dejaba claro que el único gobierno que podía existir en la Península era el romano, ya fuera el ejercido directamente por el Estado, ya por aquellos romanos que habían salido de Italia, los llamados "hispanienses", perseguidos por su oposición al régimen establecido e italianos asentados en Hispania antes de la Guerra Social66. Así, en cuanto Sertorio llegó a la Península se ganó a los íberos del siguiente modo:

Con su buen trato se concillaba a los poderosos y al pueblo con la
63 Cf. Plu., Aem. 4.3. Las acciones de Paulo Emilio en Hispania también son recogidas por Tito Livio XXXVI,2.8-11,;XLIII,2.5.

64 Acerca del uso del diálogo y las medidas populares de Sertorio, cf. F. GARcíA MORA, 1991, p. 25.

65 Cf. Plu., Sert. 22.6-8.

66 Acerca de la problemática del término 'P $\omega \mu \alpha i ́ \omega v$, usado por Plutarco, y su función en el bando sertoriano, cf. F. GARCÍA MORA, 1991, pp. 27 y 166-167. 
supresión de impuestos, pero sobre todo se hizo querer al liberarlos del alojamiento de las tropas ${ }^{67}$.

Pero "no hizo todo por su benevolencia con los bárbaros, sino que armó a los romanos que habitaban allí y estaban en edad militar, (...) siendo civilizado en sus relaciones en la paz y mostrándose temible en la preparación de los efectivos para la guerra".

El siguiente paso, una vez conseguida la concordia, fue crear una serie de instituciones a imagen de las romanas, con lo que consiguió, por un lado, ofrecer una alternativa a los "hispanienses"68, "al haber llamado senado ( $\sigma 0 ́ v \kappa \lambda \eta \tau o v)^{69}$ a

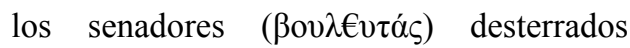
de Roma que se encontraban con él y designar sus cuestores ( $\tau \alpha \mu i ́ \alpha \varsigma$ ) y pretores $(\sigma \tau \rho \alpha \tau \eta \gamma o v ́ \varsigma)$ de entre ellos..."70. Por otro lado, dinamizaba el proceso de romanización íbero, junto con innovaciones como la educativa, ya referida. No obs- tante, como Plutarco deja claro, toda esta reforma la realizaba "con la idea de adquirir la libertad para los romanos, no para engrandecer a los íberos contra Roma"71. Otra institución también creada por Sertorio es el tribunal, en el que se daba audiencia a quien se lo pedía ${ }^{72}$.

Pero esta situación no debía ser tan favorable para los hispanos, ya que, según las palabras de Plutarco, puestas en boca de Perpena, la situación de los "hispanienses" era semejante a la de íberos y lusitanos, "aguantando insolencias, mandatos y sufrimientos no inferiores" . Esto implica que los hispanos continuaban, bajo el gobierno de Sertorio, en una situación desfavorable. Aún se complicó más la política sertoriana cuando sus gobernantes se vieron salpicados por la corruptela ${ }^{74}$ :

...la mayoría (,scil. los aliados romanos de Sertorio) no se sublevaba abiertamente por temor de su
67

68 Se sitúa la configuración del senado en el invierno del 77 al 76 a.C., cf. F. GARCíA MORA 1991, pp. 181-182.

69 Esta institución, formada por sus pí̉ou (cf. App., BC. 1.108), únicamente tendría valor consultivo, resolviendo personalmente Sertorio las cuestiones; cf. Plu., Sert. 23.5-6.

70 Cf. Plu., Sert. 22.5 y 23.5.

71 Cf. Plu., Sert. 22.7-8. Sobre la intención sertoriana de romanizar a los indígenas hispanos, cf. F. GARCíA MORA, 1991, p. 367.

72 "Sertorio usaba las asambleas indígenas para sus propios fines, básicamente canalizar el poder judicial; con ello no dañaba su imagen ni recortaba directamente la autonomía de sus aliados, pese a que en realidad ésta se viese seriamente mermada", cf. F. GARCÍA MORA, 1991, p. 181.

73 Cf. Plu., Sert. 25.3.

74 Cf. Plu., Sert. 25.4-6. 
poder, pero en secreto iba perjudicando sus empresas y maltrataba a los bárbaros, castigándoles duramente y sometiéndoles a tributos, como si fueran órdenes de Sertorio. Por esto se produjeron defecciones y revueltas en las ciudades. Los enviados para curar y mitigar estos problemas regresaban tras haber suscitado más guerras....

Entonces, la política íbera, hasta ese momento fiel a Sertorio, comienza a hacer defección ${ }^{75}$ y se pasa al recién llegado bando pompeyano ${ }^{76}$, sobre todo tras la muerte de su líder en la conjura de Perpena (ca. 73-72 a.C). La situación ya de por sí resultaba insostenible y Perpena, con los pocos aliados que aún le quedaban, no pudo sino ser derrotado por Pompeyo, con lo que las esperanzas de libertad íberas se desvanecieron. Es reseñable que el pueblo hispano no fue el culpable de la muerte de Sertorio, aunque Plutarco lo califica de traicionero contra su general por sus defecciones, ni aún sufriendo los desmanes de su gobierno, pues, como el de Queronea resalta, "Sertorio tenía una escolta de muchas miríadas de hombres dispuestos a sufrir el sacrificio final por él"78. Fueron los "hispanienses" conjurados, con Perpena a la cabeza ${ }^{79}$, quienes dieron muerte al general romano, trasladando a la Península ibérica las guerras intestinas que asolaban la itálica.

La política de Sertorio, gracias a la conservación de una cierta estabilidad no exenta de enfrentamientos contra los ejércitos enviados desde la Urbs, transciende los límites físicos de Hispania . Mitrídates VI Eupátor, rey del

No es la única defección íbera que describe Plutarco, caracterizando a los pueblos hispanos, en cierto modo, de traicioneros, cf. Plu., Cat. Mi. 59.9; Galb. 29.3. También describe deserciones de la milicia íbera, cf. Plu., Cat. Ma. 11.2-3; Marc. 12.6. En este pasaje, además, destaca la importancia que tuvo la caballería íbera como componente de los ejércitos romanos.

También Pompeyo hizo un gran esfuerzo por atraerse la amistad de los íberos, cf. Plu., Pomp. 18.1-2: "Atrajo hacia sí a los pueblos que no estaban muy firmemente asociados con Sertorio y los transformó".

77 Cf. Plu., Sert. 27.1. Acerca de las causas de la muerte de Sertorio y el futuro del bando hispaniense, cf. F. GARCÍA MORA, 1991, pp. 346-347.

79

80

81 Cf. Plu., Sert. 14.5-6.

Cf. Plu., Pomp. 20.3: "Entre tanto murió Sertorio, asesinado traidoramente por sus amigos".

Tanto por sus medidas en política intema como extema, la política de Sertorio reúne características que parecen describir un régimen parecido al de la monarquía: los lusitanos envían mensajeros al general íbero é $\varphi$ ' $ү \gamma \beta \mu o v i \alpha$ (cf. Plu., Sert. 10.1) y éste actúa

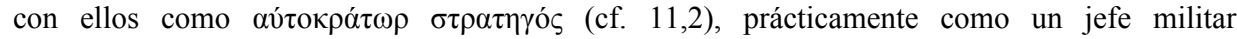
helenístico (cf. Plu., Eum. 20.2); cf. D. PLÁCIDO, 1989, pp. 98-99.

Cf. Plu., Sert. 23-24. Acerca de la problemática del tratado entre Mitrídates y Sertorio, cf. F. GARCÍA MORA, 1991, pp. 287-298. 
Ponto, conocedor de la fama de Sertorio, extendida ya hasta el Mediterráneo oriental, decide mandar una embajada al general romano, en la que solicita, en primer lugar, un pacto por el cual pueda ocupar algunas regiones de la actual Turquía que antes pertenecieron a su reino; en segundo lugar, le pide apoyo militar, principalmente de infantería, a cambio de dinero y fuerzas navales de las que carecía el bando "hispaniense"82. Sertorio actuó como si Hispania se tratara de la capital del imperio: se dirigió al senado y decidió que le apoyaría en todo, excepto en la ocupación de territorios que legítimamente pertenecieran a Roma.

Tras estos tratados (ca. 75-74 a.C) el de Queronea recoge cómo, atendiendo a las peticiones de Mitrídates, Sertorio llegó a enviar parte de su contingente con Marco Mario a la cabeza y que incluso en estas tierras asiáticas el ejército, en nombre de su general, se comportó políticamente como lo hiciera en Hispania, suprimiendo los impuestos y acabando con "los excesos y desprecios de las tropas acampadas". Por esto el territorio conquistado "se exaltaba en esperanza y ansiaba el aguardado cambio de gobierno".

Este acuerdo hispano-romano con el rey Mitrídates no es el único ejemplo de contactos sertorianos con fuerzas externas a Iberia, pues también Plutarco se refiere a unas cartas de Sertorio en las que se demostraba que el general era afecto a "cónsules y hombres muy poderosos en Roma, que llamaban a Sertorio a Italia, como deseosos muchos de una revolución y de cambiar el sistema de gobierno" . Así, queda constancia de los primeros pasos, al menos para el de Queronea, de una política exterior hispana llevada a cabo por un renegado romano.

Galba propone idéntica política interior de concordia, aunque el legado de la Tarraconense del 60 al 68 d.C. no tuvo que enfrentarse a una Hispania guerrera e indómita, sino a una ya romanizada . De este modo, ante los desmanes de los procuradores que saqueaban las provincias con crueldad y dureza, Galba demuestra cierta empatia con los íberos: “...al parecer, compasivo \{scil. con los íberos) y ofendido con ellos \{scil. los procuradores romanos) ofrecía sencillamente
82

Parece ser que las fuerzas navales cilicias llegaron a Hispania, a tenor de la dura resistencia ejercida por las regiones portuarias, pero no así los tres mil talentos acordados; cf. F. GARCía MORA, 1991, p. 293.

83

Senador marianista refugiado con Sertorio, posiblemente se trate del Mario enviado a tierras de Arévacos y Pelendones, el 76 a.C.; cf. F. García Mora, 1991, p. 297.

84

Cf. Plu., Sert. 27.3-5; cf. Mor. 7.

85 Cf. Tac., Hist. 1.49; Suet., Galba. 9. El relato de Suetonio es notablemente distinto al de Tácito y Plutarco. Este último amplia el relato de Tácito, complicando la identificación de la fuente plutarquea. 
cierto respiro y consuelo a los injuriados y vendidos". De hecho, los íberos sólo muestran su indignación contra el poder de Roma "cuando se componían canciones contra Nerón y se difundían y cantaban por todos los lugares".

Trabajo.

Igualmente parco en datos se muestra el de Queronea con respecto a esta esfera social, que relativamente se puede reconstruir a través de las breves alusiones que recoge en Moralia y Vidas. Más interesado por el valor moral de su obra, Plutarco describe a los íberos siguiendo una directriz clara, según la cual éstos contaban entre los pueblos bárbaros que poco interés podían ofrecer fuera del proceso romanizador. Así, la principal ocupación de los Hispanos era el bandidaje en sus distintas formas. Cayo Mario fue el primero que, como propretor de la Iberia Ulterior, intentó atajar los problemas de bandidos en su provincia: “...limpió la provincia de bandidos, pues estaba aún sin civilizar y era feroz en sus costumbres, y los íberos consideraban aún entonces el bandidaje como un oficio honroso" . La misma fuente de ingresos tenían los caracitanos, a los que ya se ha hecho referen- cía, y los ligures que habitaban la zona de costa de los Alpes, bañada por el mar Tirreno. Éstos se dedicaban a llevar sus ataques "al mar con barcos piratas, robaban y saqueaban las naves mercantes, navegando hasta las columnas" , en tiempos del consulado de Paulo Emilio.

Posteriormente, en el relato de la vida de Sertorio, Plutarco ya no hace mención apenas de bandidaje en la Península ibérica, sino de otras formas menos violentas de obtener ganancias, pero igualmente deshonestas, como el cobro excesivo de peajes: “...se veía obligado por los bárbaros a pagar tasas (scil. Sertorio) y derechos de peaje. Los que iban con él se sentían irritados y consideraban indigno que un procónsul romano pagara tasas a unos miserables bárbaros".

Ante esta situación, fruto de los primeros influjos de la romanización en Hispania, los generales venidos de Italia utilizarán esa impetuosidad para sus fines, contratándolos como soldados o escoltas: “...tenía (scil. Mario)

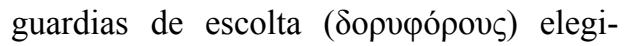
dos de entre los esclavos que acudían a él, a los cuales llamaba Vardieos..."90. Igual trabajo ofrecen Sertorio o Pompe-

86 Cf. Plu., Galb. 4.1.

${ }^{87}$ Cf. Plu., Mar. 6.1-2.

${ }^{88}$ Cf. Plu., Aem.6.2-3.

89 Cf. Plu., Sert. 6.4-5. Probablemente, este pueblo sea el de los cerretanos; cf. G. FATÁs CABEZA, “¿A quién engañó Sertorio cuando cruzó el Pirineo?”, IV Colloqui d'Arqueología de Puigcerdá, Puigcerdá, 1983, pp. 235-238

90 Cf. Plu., Mar 43.4. 
yo $^{91}$ a los íberos a su llegada, de forma que en ocasiones posibilitaban un sincretismo ibero-romano en sus tácticas de combate, como ocurre en el caso del primero .

Otro trabajo que aparece en los escritos de Plutarco es el de los prestamistas, que debieron de experimentar gran auge a tenor de la romanización y de la abundante acuñación de moneda en Hispania. Se tienen noticias de esta labor en los pueblos lusitanos y galaicos por una alusión en la Vida de César, según la cual el general romano corrigió "las desavenencias entre deudores y prestamistas", por medio del pago fraccionario. Junto a esta profesión se encuentra la de los compradores de propiedades, como los que se presentaron para adquirir las posesiones de Nerón en Hispania, tras poner en venta sus bienes una orden del ya emperador Galba ${ }^{94}$. En este último caso no se puede saber si los compradores eran indígenas hispanos o romanos afincados en la Península.

También Plutarco hace referencia a compras o uso de esclavos, como los citados hijos de íberos nobles vendidos por Sertorio tras la descomposición de la "escuela" de Osea, los habitantes de Cástulo que se salvaron de la muerte tras rebelarse contra el ejército sertoriano (97 a.C. $)^{95}$, los "tres muchachitos de entre los prisioneros" que compró Pació (ca. 195 a.C.), uno de los servidores de Catón el Antiguo ${ }^{96}$, o las jóvenes sirvientas de Vibio Paciano97, que acompañaron a Marco Licinio Craso en su refugio, el 83 a.C., dentro de una cueva,
Acerca de esta anécdota, cf. R. Ma . AGUILAR, "Dos paisajes españoles en Plutarco", en J. GARCÍA LÓPEZ-E. CALDERón (ed.), Estudios sobre Plutarco: paisaje y naturaleza, Madrid 1991, pp. 221-226. 
durante ocho meses y que en su vejez recordaban esta anécdota.

Sin embargo, resulta muy escasa la información que se ofrece sobre otros sectores económicos como la agricultura, acerca de la cual tan sólo se describe la excelsitud de los terrenos de las Islas Afortunadas, "región buena y fértil para arar y plantar" hasta tal punto que produce "cosechas espontáneas, suficientes por su cantidad y calidad para alimentar sin esfuerzos ni trabajo a un pueblo ocioso"99. Además de este idílico paisaje Plutarco tan sólo da noticia de un envío de trigo a Roma durante el consulado de Cayo Graco. Según esta anécdota, el propretor Fabio Máximo, acostumbrado a la corrupción y exacción contra el pueblo hispano fue censurado el año 123 a.C. por Cayo Graco, quien solicitó al senado que el dinero obtenido por el trigo fuera pagado a sus productores hispanos $^{100}$. La ganadería no aparece en sus escritos y sólo se cuenta con una referencia a la caza, inserta en la anécdota de la cierva blanca de Sertorio ${ }^{101}$.

Más sorprendente parece que el de Queronea no haga apenas mención de la rica metalurgia y orfebrería íberas, de las que se conservan abundantes restos arqueológicos. Tan sólo se encuentra una alusión a la manera de trabajar el hierro en Moralia: "Pues como los celtíberos templan el hierro, cuando, después de haberlo metido en la tierra, le quitan la mayoría de las impurezas" . Y acerca de la orfebrería se podrían contar con ciertos indicios en el rico adorno que presentaban, según Plutarco, los caballos de generales como el de Pompeyo: "llevaba un frontal de oro y arreos de gran valor"103. Otra noticia aparece cuando Plutarco relata las enseñanzas de Sertorio a los íberos: "Sin escatimar el oro y la plata adornaba sus cascos y embellecía sus escudos, enseñándoles a usar capas y túnicas bordadas, y se hacía popular subviniendo a estos gastos y compartiendo con ellos su amor por la belleza"104.

\section{CONCLUSIÓN.}

A tenor de los textos examinados, la conclusión que se puede extraer, en primer lugar, es que Plutarco no se interesó especialmente por la sociedad íbera hasta su madurez (96 al 120 d.C.), cuando, al

99 Cf. Plu., Sert. 8.3-4. Cf. C. B. Pelling, "Truth and Fiction in Plutarch's Lives", en D. A. Russell (ed.), Antonine Literature, Oxford, 1990, pp. 30-31; R. Mª. Aguilar-L. PÉREZ VILATELA, 2004, p. 62 n. 59, con una extensa bibliografía.

100 Cf. Plu., CG. 6.2.

${ }^{101}$ Cf. Plu., Sert. 11.3.

102 Cf. Plu., Mor. 17.510F.

103 Cf. Plu., Pomp. 19.5-6; Plu., Sert. 19.8.

104 Cf. Plu., Sert. 14.2-3. Los hispanos estaban acostumbrados a presentarse en el campo de batalla vistiendo sus mejores galas y portando bellas armas como falcatas, vainas, faleras o yelmos. 
tratar personajes como Paulo Emilio, Pompeyo, Sertorio, César, Craso y Mario, que tuvieron un contacto con la Península, inserta muy breves referencias ${ }^{105}$. En Moralia apenas incluye noticias de interés para el tema tratado.

En segundo lugar, Plutarco no debió conocer mediante autopsia Hispania, ni a los íberos, y hubo de extraer su información de autores anteriores a él o contemporáneos, fuentes sobre las que la filología moderna ha hecho importantes estudios.

Finalmente, se ha de resaltar que Plutarco abunda en la información referente a la milicia, elemento clave para la descripción de sus personajes; sin embargo, resulta parcial como fuente para la sociedad íbera, de modo que es difícil dibujar un cuadro fidedigno a partir de sus breves noticias, en muchos casos, cargadas de prejuicio helenocentrista.

Por tanto, para la reconstrucción histórica, la utilización de los textos plutarqueos -aunque no carecen de interés, cuando sus noticias tienen paralelos en otros autores antiguos o son comprobables por los restos arqueológicos-, debe hacerse con gran precaución.

En resumen, Plutarco describe una sociedad altamente primitiva, supersticiosa y tribal, caracterizada por cierto valor y agresividad militar, pero que, sin la dirección de un general romano, no tiene más utilidad que la de un servicio ofrecido por bandoleros. Tampoco interesa a Plutarco la influencia ejercida por el proceso romanizador en Hispania, por lo que, a lo largo de su obra, considera el pueblo íbero simplemente como un pueblo bárbaro más.

\section{BIBLIOGRAFÍA}

AALDERS, C. J. D.,

- Plutarchs Political Thought, Amsterdam, 1983.

AgUILAR, R. Ma.,

- "Política romana en Hispania", en I.

GALlO-B. SCARDIGLI (ed.), Teoría e prassi politica nelle opere di Plutarco. Atti del $V$ Convegno plutarcheo, Certosa di Pontignano, $\quad$ 7-9 giugno 1993,

Nápoles, 1993, pp. 15-28.

- Fontes Historiae Antiquae IV (en prensa).

Aguilar, R. Ma . - PÉrez Vilatela, L.,

- Plutarco, Vidas de Sertorio y Pompeyo, Madrid, 2004.

BENNETT., W.,

- "The death of Sertorius and the coin", Historia, 10 (1961)459-467.

BLÁZQUEZ, J. Ma.,

- "La religiosidad de los pueblos hispanos vista por los autores griegos y latinos", Emérita, 26 (1958) 79-110.

- Religiones primitivas ibéricas tomo II. Religiones prerromanas, Madrid, 1983.

GARCÍA MORA, F.,

Un episodio de la Hispania republicana: la guerra de Sertorio, Granada, 1991.

GARcía Moreno, L. A.,

- "Paradoxography and Political Ideáis in Plutarch's Life of Sertory", en PH. A. Stadter (ed.), Plutarch and the Historical Tradition, Londres y Nueva York, pp. $132-158$

${ }^{105}$ Constituyen las parejas XIII-XIV a XVI-XXIII, cf. C. P. JONES, “Towards a Chronology of Plutarch's Works", Journal ofRomans Studies, 56 (1966) 61-74. 
GILLIS, D.,

- "Quintus Sertorius", R1L, 103 (1969) 711-727.

PÉREZ PEIX, D’Ors,

- "Sobre los orígenes del culto al emperador en la España romana", Emérita, 10 (1942) 197-227.

PLÁCIDO, D.,

- "Sertorio", Studia Histórica, Historia Antigua, 7 (1989) 90-110.

Rodríguez Adrados, F.,
- "La fides ibérica", Emérita, 14 (1946) 128-209.

SALINAS DE FRÍAS, M.,

- "La religión indígena de la Hispania central y la conquista romana", Hispania Antiqua, 11-12 (1981-1985) 302-325.

SCHULTEN, A.,

- Fontes Hispaniae Antiquae III, Barcelona, 1935.

- Sertorio, Barcelona, 1949. 